\title{
Chronic endometritis modifies decidualization in human endometrial stromal cells
}

Di Wu ${ }^{1,2}$, Fuminori Kimura ${ }^{1 *}$ D, Luyi Zheng ${ }^{1}$, Mitsuaki Ishida ${ }^{3}$, Yoko Niwa ${ }^{1}$, Kimiko Hirata ${ }^{1}$, Akie Takebayashi ${ }^{1}$, Akiko Takashima ${ }^{1}$, Kentaro Takahashi ${ }^{1}$, Ryoji Kushima ${ }^{4}$, Guangmei Zhang ${ }^{2 *}$ and Takashi Murakami ${ }^{1}$

\begin{abstract}
Background: Chronic endometritis (CE) is a continuous inflammation of uterine endometrium, and it is usually symptomless. As CE has been thought not to affect the reproductive status and general health of affected women, its significance has not been explored. However, recent studies have shown that CE is related with repeated implantation failures after in vitro fertilization-embryo transfer, unexplained infertility, and recurrent miscarriages. As decidua differentiates to support the implantation process and maintains the pregnancy, we hypothesized that CE may influence the process of decidualization.
\end{abstract}

Methods: Seventeen patients were employed in the experiment involving culture of endometrial stromal cells (ESCs). After obtaining endometrial samples, ESCs were harvested and cultured for 13 days. The concentrations in culture media and the protein expressions in ESCs of prolactin (PRL) and insulin-like growth factor binding protein-1 (IGFBP-1), two well known decidualization markers used in a large number of in vitro models, were analyzed by ELISA and Western blotting, respectively, and the cell numbers were also counted. The mRNA levels of PRL and IGFBP-1 were tested by quantitative real time polymerase chain reaction (RT-PCR). Since sex hormone induce proliferation and differentiation to decidua via binding to the sex hormone receptors (ERa, ERß, PRA, and PRB), their expression was assessed in another 17 patients' paraffin-embedded endometrial tissue specimens by immunohistochemistry and semi-quantified by H-score.

Results: Increased cell numbers and reduced secretion of PRL and IGFBP-1 were detected by ELISA in the ESCs of CE patients after culture for 13 days compared with non-CE patients. The decreased protein expression of IGFBP-1 in ESCS of CE patients was detected by Western blotting. The decreased expression of PRL mRNA and IGFBP-1 mRNA were detected by RT-PCR. Increased expressions of ERa, ER $\beta$, PRA, and PRB were observed in the stromal cells of CE patients in comparison to non-CE patients, whereas increased expressions of ERa and ER $\beta$ were detected in the glandular cells of CE.

Conclusion: Our data suggests that CE modifies decidualization of human ESC through untuning the function of sex steroid hormone receptor.

Keywords: Chronic endometritis, Decidualization, IVF, Endometrial stromal cells, Sex hormone receptor

\footnotetext{
* Correspondence: kimurafu@belle.shiga-med.ac.jp;

GuangmeiZhang@126.com

${ }^{1}$ Department of Obstetrics and Gynecology, Shiga University of Medical

Science, Seta Tsukinowa-cho, Otsu 520-2192, Japan

²Department of Obstetrics and Gynecology, 1st Affiliated Hospital, Harbin

Medical University, Harbin, Heilongjiang Province 150001, China

Full list of author information is available at the end of the article
}

(c) The Author(s). 2017 Open Access This article is distributed under the terms of the Creative Commons Attribution 4.0 International License (http://creativecommons.org/licenses/by/4.0/), which permits unrestricted use, distribution, and reproduction in any medium, provided you give appropriate credit to the original author(s) and the source, provide a link to the Creative Commons license, and indicate if changes were made. The Creative Commons Public Domain Dedication waiver (http://creativecommons.org/publicdomain/zero/1.0/) applies to the data made available in this article, unless otherwise stated. 


\section{Background}

Chronic endometritis (CE) is a disease of continuous and subtle inflammation of the uterine endometrium. It is also called subclinical endometritis because it is usually symptomless or presents only with subtle symptoms such as abnormal uterine bleeding, pelvic pain, dyspareunia, and leucorrhea [1]. CE was thought to be caused by a variety of infectious agents such as bacteria, viruses, and parasites, but the precise cause of CE remains unclear [2]. It is diagnosed by the presence of plasma cells, which are never present under normal conditions, within the endometrial stromal layer to show the existence of a continuous immune response to some substance(s) or agent(s) in the endometrium [1, 3].

Since CE has been thought not to affect the reproductive status and general health of affected women [1], its significance has not been explored. However, recent research has shown a higher prevalence of $\mathrm{CE}$ in infertile patients (range 2.8 to $46 \%$ ) [4-8] and relationships with recurrent abortion and repeated implantation failure $[4,9,10]$. Furthermore, a new clinical study reported that $\mathrm{CE}$ decreases the success rate of in vitro fertilization (IVF) [11]. These results suggest that CE affects uterine receptivity for the embryo and impairs successful pregnancy.

Endometrial stromal cells (ESCs) undergo the process of decidualization [12]. Decidua is transformed under the influence of estrogen and progestogen and differentiates to maintain the pregnancy. It exchanges nutrition, gas, and waste between the fetus and mother in cooperation with the placenta. Decidua also produces hormones, growth factors, and cytokines such as prolactin (PRL) [12-14], corticotrophin releasing factor (CRF) $[15,16]$, insulin-like growth factor binding protein-1 (IGFBP-1) [12, 17], and interleukin-15 $[18,19]$. It may regulate the invasion of the trophoblast and the attack from the maternal immune system [20, 21]. Given the adverse effects of CE on the implantation process in clinical studies and the role of decidua, CE may modify the process of decidualization.

Another gynecological disease that may cause infertility and implantation failure is endometriosis, affecting $10-15 \%$ women of reproductive age $[22,23]$. It is characterized by the appearance of hormone-sensitive endometrial-like tissue outside the uterine cavity [24]. Eutopic ESCs from endometriosis patients exhibit a reduced response to decidualization in primary culture, which suggests that abnormal differentiation of the eutopic endometrium is related to infertility $[25,26]$. Recently, an article reported that $52.94 \%$ of endometriosis patients are diagnosed with CE compared to only $27.02 \%$ of non-endometriosis patients [27]. This fact also suggests that CE may be involved in the modification of decidualization in eutopic endometrium.

To explore the effects of CE on decidualization, the expressions of PRL and IGFBP-1, markers of decidualization, were analyzed in primary culture of human ESCs. In addition, the expressions of sex steroid hormone receptors, estrogen receptors $\alpha$ and $\beta(\mathrm{ER} \alpha, \mathrm{ER} \beta)$ and progesterone receptors $\mathrm{A}$ and $\mathrm{B}$ (PRA, $\mathrm{PRB}$ ) were analyzed by immunohistochemistry.

\section{Methods \\ Collection of samples for culture experiment}

The patients underwent urine LH testing provided from our hospital daily from 3 or 4 days before the estimated ovulation date. On the day or the day after the urine test became positive, the patients visited our hospital and the status of follicle growth was confirmed. When follicle growth was sufficient as preovulatory follicle, the patient was planned to undergo hysteroscopy and curettage at 7 or 8 days after predicted ovulation. When endometrial polyps were found at hysteroscopy, the patients were excluded. On the day of hysteroscopy and curettage, blood samples were obtained to measure serum levels of estradiol (E2) and progesterone (P4). Endometrial tissue obtained by first curettage from each patient was sent to the pathology department. Mild curettage was performed a few more times to obtain endometrial tissue for the culture experiment. The tissues of first curettage were fixed in $10 \%$ formaldehyde, embedded in paraffin, and sectioned at $4 \mu \mathrm{m}$. According to the criteria of Noyes et al., the section was stained with hematoxylin and eosin for histological examination and judging of the date of the endometrial phase [28]. Moreover, the sections were immunostained with anti-CD138 antibody (product no.B-A38, Nichirei Corp.) as we previously reported or used for immunostaining for sex steroid hormone receptors. The criteria of $\mathrm{CE}$ diagnosis was the observation under microscopy with a high powered field of two or more CD138-positive cells in the stromal layer [29]. The diagnosis of CE and endometrial dating was performed by investigators (FK, MI) and the investigators performing the culture experiments (DW, LZ, YN) were blinded to the CE status of the sample until all procedures of cell culture, cell counting and ELISA were completed and all results were obtained.

The patients' age, parity, gravidity, body mass index (BMI), endometrial thickness, and causes of fertility including the diagnosis of endometriosis were obtained from the patients' records. Endometriosis was diagnosed when the existence of endometrioma was confirmed by MRI or stage III or IV endometriosis was confirmed by laparoscopy within 2 years before participation in this study. The information with endometriosis was used for the subanalysis of following experiment as endometriosis may affect the result.

\section{Isolation and culture of ESCs}

The endometrial tissues obtained from 17 patients, nine CE patients including five endometriosis patients and 8 
non-CE patients including 4 endometriosis patients, were used to perform primary cell culture as we previously reported [30]. Briefly, after mince, these endometrial tissue pieces were incubated for $1 \mathrm{~h}$ at $37{ }^{\circ} \mathrm{C}$ in a humidified atmosphere of $5 \% \mathrm{CO}_{2}$ in air with $0.2 \%$ collagenase (Sigma) and $0.005 \%$ deoxy ribonuclease I (Worthington Biochemical Co.), with gentle pipetting every $15 \mathrm{~min}$. After digestion, $20 \mathrm{~mL}$ of DMEM/F12 $(1: 1)(1 \times)$ (Life technologies) replenished with 10\% charcoal striped FBS (HyClone GE Healthcare Life Sciences) were added, and the cell suspension was placed in the upright position for $3 \mathrm{~min}$. Then, the supernatant including the rich fraction of stromal cells was filtered through the $40-\mu \mathrm{m}$ cell strainer (Falcon Life Sciences) and then centrifuged for $10 \mathrm{~min}$ at room temperature. After the pellet was resuspended, a total of 400,000 viable cells per well were transferred into six well multidish (Thermo Fisher Scientific). The ESCs were cultured at $37{ }^{\circ} \mathrm{C}$ in a humidified atmosphere of $5 \% \mathrm{CO}_{2}$ in air with $2 \mathrm{~mL}$ of DMEM replenished with $10 \% \mathrm{FBS}$, $100 \mathrm{IU} / \mathrm{mL}$ penicillin, and $100 \mu \mathrm{g} / \mathrm{mL}$ streptomycin. After $1 \mathrm{~h}$, the culture media were exchanged to culture media including estradiol $3 \times 10^{-10} \mathrm{~mol} / \mathrm{L}(81.7 \mathrm{pg} / \mathrm{mL})$ (Sigma) and progesterone $5 \times 10^{-8} \mathrm{~mol} / \mathrm{L}(15.7 \mathrm{ng} / \mathrm{mL})$ (Nacalai Tesque, Inc.). The culture media were changed every other day, and the ESCs were cultured for 13 days. The culture media were changed $24 \mathrm{~h}$ before the collection of culture media and cell harvest. The culture media were collected, centrifuged at room temperature followed by the collection of supernatant, and stored at $-80{ }^{\circ} \mathrm{C}$ for later analysis. The numbers of ESCs in a dish were counted by the inverted microscope with cell counter after exposure to $1 \mathrm{~mL}$ of $0.05 \%$ trypsin and $0.02 \%$ EDTA in PBS for a few minutes, followed by deactivation by adding $1 \mathrm{~mL}$ of DMEM/F12 with 10\% FBS.

\section{ELISA to detect PRL and IGFBP-1 in culture media}

The levels of PRL and IGFBP-1 in culture media were measured by ELISA kits (Prolactin Picokine ELISA Kit, Product no. EK0593, Boster Biological Technology. Ltd.; Human Free IGFBP-1 Quantikine ELISA Kit, Product no. DGB100, RSD R\&D Systems Inc.) following the manufacturers' instructions. The concentrations of PRL secreted by a cell was calculated by the formula: [PRL] $\mathrm{x}$ [volume ratio]/cell number. Where [PRL] represents the concentration of PRL in culture media assessed by ELISA (pg/L), and [volume ratio] indicates the actual volume of collected medium in one well $(\mathrm{mL})$ divided by $2 \mathrm{~mL}$ (the initial volume of culture media). Cell number means the total cell number in the well. The concentration of IGFBP-1 secreted by a cell was obtained using an identical calculation.

\section{Protein extraction from cultured cells and western blotting}

After discarding the supernatant, the cells on wells were washed twice with PBS. RIPA buffer $(200 \mu \mathrm{L}: 20 \mu \mathrm{L} 1 \%$ SDS, $20 \mu \mathrm{L}$ RIPA Buffer with protease inhibitor cocktail and $160 \mu \mathrm{L}$ DW, Nacalai Tesque, Inc.) was added to the well. The cells on wells were cooled for $5 \mathrm{~min}$ on ice, collected with the cell scraper to be homogenized, and centrifuged at $10000 \times \mathrm{g}$ at $4{ }^{\circ} \mathrm{C}$ for $10 \mathrm{~min}$. The supernatant was collected and kept at $-80{ }^{\circ} \mathrm{C}$ until used for Western blotting.

The protein $(10 \mu \mathrm{g})$ was boiled in Laemmli solution under reducing condition at $95{ }^{\circ} \mathrm{C}$ for $7 \mathrm{~min}$. The solutions from $\mathrm{CE}$ and non-CE patients and Protein Ladder One Triple-color (Nacalai Tesque) were electrophoresed on a $15 \%$ SDS-polyacrylamide gel (Wako Pure Chemical Industries) and then transferred to a polyvinylidene difluoride membrane (Millipore). Membranes were incubated with $20 \%$ blocking reagent-N102 (NOF Co.) in $25 \mathrm{mM}$ TBS containing 0.1\% Tween-20 (TBST; pH 7.4) at room temperature for $1 \mathrm{~h}$ to block non-specific protein binding sites, followed by incubation with the IGFBP-1 antibody (1: 1000; Santa Cruz Biotechnology, Inc.) or GAPDH (1:5000; Enzo Life Science, Inc.) diluted by TBST at $4{ }^{\circ} \mathrm{C}$ overnight. After washing with TBST for 20 min thrice, the membranes were reacted with a peroxidase-labeled anti-mouse IgG (1:50,000; GE Healthcare) for $1 \mathrm{~h}$ at room temperature. Peroxidase labeling was detected by chemiluminescence using the Chemi-Lumi one super (Nacalai Tesque).

\section{RNA extraction from culture cells and real-time polymerase chain reaction}

Total RNA was extracted from ESCs after culture for 13 days with RNeasy Micro kit (QIAGEN.) following the manufacturer's instructions. Each sample (100 ng) was reverse transcribed using the Prime Script RT Master Mix (Takara Biotechnology. Co., Ltd.). Real-time PCR was performed using the LightCycler 480 SYBR Green I Master (Roche Diagnostics International Ltd.) with specific primer pairs for PRL, IGFBP-1 and GAPDH as follows: PRL, F:5'- GCCCCCTTGCCCATCTGTCG-3' and R:5' - AGAAGCCGTTTGGTTTGCTCC -3'; IGFBP1, F:5' - TGCTGCAGAGGCAGGGAGCCC -3' and R:5'AGGGATCCTCTTCCCATTCCA -3' (Takara); GAPDH, F:5'- AAATCCCATCACCATCTTCCA -3' and R:5'AATGAGCCCCAGCCTTCTC -3' (Sigma).

The mixture of reaction reagents was incubated at $95^{\circ}$ $\mathrm{C}$ for $5 \mathrm{~min}$ and cycled according to the following parameters: $95{ }^{\circ} \mathrm{C}$ for $10 \mathrm{~s}, 55{ }^{\circ} \mathrm{C}$ for $15 \mathrm{~s}$, and $72{ }^{\circ} \mathrm{C}$ for $10 \mathrm{~s}$ for a total of 45 cycles, followed by cooling for $10 \mathrm{~s}$ at $50{ }^{\circ} \mathrm{C}$ by LightCycler $480 \mathrm{TL}$ system II (Roche Diagnostics International Ltd.). Melting curve analysis was performed. 
Immunohistochemistry for endometrial tissue specimens The stocked paraffin-embedded endometrial tissue specimens obtained from 156 infertile patients from 7 to 8 days after ovulation to diagnose the endometrial dating and $\mathrm{CE}$ were the candidates for the study of immunohistochemistry. The diagnosis of CE was done by the same method of the culture experiment of the present study. If endometrial disease such as endometrial hyperplasia or polyp were diagnosed, the samples were excluded from the study. Seventeen samples (eight samples of CE and nine samples of non-CE) were randomly chosen for the analysis by an investigator (FK) when the endometrial dating of the phase in the endometrium pathologically determined according to the criteria of Noyes et al. was in the phase between 7 and 9 days in the secretory phase [28]. At that time the investigator was blinded to the patients' character except the diagnosis of $\mathrm{CE}$ and endometrial dating. The patients' age, parity, gravidity, BMI, endometrial thickness, and causes of fertility were obtained from the patients' records after the following experiments of immunohistochemistry were completely diagnosed by other investigators.

The paraffin-embedded blocks were cut into 4- $\mu \mathrm{m}$ thick sections. After deparaffinization and rehydration, the slides were immersed into $3 \%$ Tritonx-100 in PBS for $15 \mathrm{~min}$ and heated in a pre-heated sodium citrate buffer (pH 6.0) at $98{ }^{\circ} \mathrm{C}$ for $20 \mathrm{~min}$. After infusion in $3 \%$ hydrogen peroxide for $10 \mathrm{~min}$, the sections were covered with 5\% BSA in PBS for 25 min followed by incubation with the primary antibodies as follows: ER $\alpha$ (1:50; Product no. sc-8005, Santa Cruz Biotechnology) at $4{ }^{\circ} \mathrm{C}$ for 3 days, and $\operatorname{ER} \beta$ (1:200; Product no. ab288, Abcam), PRA (use directly;Product no. PA0312, Leica Biosystems Newcastle Ltd.) and PRB (1: 200; Product no.3157S, Cell Signaling Technology, Inc.) at $4{ }^{\circ} \mathrm{C}$ overnight, incubated with horseradish peroxidase-conjugated secondary antibody for $30 \mathrm{~min}$ at room temperature, and developed with DAB. The slides were immersed into hematoxylin counterstain for $1 \mathrm{~min}$, underwent gradient alcohol dehydration followed by the xylene process, and mounted with neutral resin for later observation under an inverted microscope (BH-2, Olympus Co.).

\section{Scoring of immunoreactivity for endometrial tissue specimens}

In order to semi-quantitatively analyze the immunoreactivity of nuclear steroid receptors, the $\mathrm{H}$-score was used [31]. Briefly, the cells of more than 500 ESCs or glandular cells were each scored using three degrees: strongly stained nuclei (two points), moderately stained nuclei (one point), and negative stained nuclei (zero points). The H-score was subsequently calculated by summing the numbers of each point multiplied by the percentage of the point.

\section{Statistical analysis}

All data are expressed as means \pm standard error of the mean (S.E.M). An unpaired $t$-test unpaired or the Mann Whitney test was performed based on whether that distribution was Gaussian using GraphPad Prism ver.7.00. A value of $P<0.05$ was considered significant.

\section{Results}

\section{CE affects the decidualization of ESCs}

This study included samples of nine CE patients and eight non-CE patients (Table 1). Age, parity, gravidity, $\mathrm{BMI}$, the levels of $\mathrm{E}_{2}$ and $\mathrm{P}_{4}$, endometrial thickness, and the rate of out-of-phase endometrium were not different between the CE and non-CE groups.

Table 1 Clinical characteristics of the patients participating in the study for ELISA, Western blotting and quantitative RT-PCR

\begin{tabular}{|c|c|c|c|}
\hline & non-CE $(N=8)$ & CE $(N=9)$ & $P$ value \\
\hline Age (y) & $37.9 \pm 0.67$ & $35.4 \pm 1.80$ & 0.25 \\
\hline Parity & $1.00 \pm 0.33$ & $0.33 \pm 0.24$ & 0.11 \\
\hline Gravidity & $0.38 \pm 0.19$ & $0.11 \pm 0.11$ & 0.23 \\
\hline BMI $\left(\mathrm{kg} / \mathrm{m}^{2}\right)$ & $22.9 \pm 1.32$ & $22.9 \pm 1.59$ & 1.00 \\
\hline E2 $(p g / m L)$ & $117 \pm 25.0$ & $142 \pm 29.14$ & 0.54 \\
\hline P4 (ng/mL) & $9.76 \pm 1.86$ & $13.21 \pm 1.84$ & 0.21 \\
\hline Endometrial thickness (mm) & $8.89 \pm 1.03$ & $8.90 \pm 0.65$ & 0.99 \\
\hline Out of phase (\%) & $0.38(3 / 8)$ & $(0.67) 6 / 9$ & 0.35 \\
\hline \multirow[t]{4}{*}{ Cause of infertility } & Male : 3 & Male : 2 & \\
\hline & Tubal factor : 2 & Tubal factor : 1 & \\
\hline & Endometriosis : 4 & Endometriosis : 5 & \\
\hline & Unknown: 1 & Unknown: 3 & \\
\hline
\end{tabular}

Age, parity, gravidity, body mass index (BMI), the levels of E2 and P4, endometrial thickness, and the rate of out-of-phase endometrium were not different between the $C E$ and non-CE groups 
The concentration of PRL secreted by a cell was obviously decreased in the CE group compared with the non-CE group $(P<0.01)$ (Fig. 1a). In addition, the concentration of another marker of decidualization, IGFBP-1, was also significantly reduced in the CE group compared with the non-CE group $(P<0.01)$ (Fig. 1b). The cell number of decidualized ESCs after culture for 13 days was obviously increased in the $\mathrm{CE}$ group compared with the non-CE group $(P<0.05)$ (Fig. 1c).

Since decidualization has been reported to be disturbed in the eutopic endometrium of endometriosis, only the samples with endometriosis were evaluated in the $C E$ group (five patients) and non-CE group (four patients). In the patients suffering from both endometriosis and CE, the concentration of PRL tended to be decreased compared with the patients with endometriosis without CE $(P=0.09) \quad$ (Fig. 1d). The concentration of IGFBP-1 produced by cells in patients with both CE and endometriosis was decreased compared with the endometriosis patients without $\mathrm{CE}(P<0.05)$ (Fig. 1e). The cell numbers of patients with endometriosis was not increased in the $\mathrm{CE}$ group compared with the non-CE group $(P=0.11)$ (Fig. 1f).

In addition, a different expression of IGFBP-1 in ESCs between $\mathrm{CE}$ and non-CE group was detected by Western blotting $(P<0.01)$ (Fig. 2a and b). A difference in the production of IGFBP-1 was also confirmed in patients with both $\mathrm{CE}$ and endometriosis compared with the endometriosis patients without $\mathrm{CE}$ by western blotting $(P<0.05)$ (Fig. 2a and c).

The mRNA levels of PRL and IGFBP-1 were significantly lower in the $\mathrm{CE}$ group than in the non-CE group $(P<0.05)$ (Fig. 3a and b). When only the samples with endometriosis were evaluated in the $\mathrm{CE}$ group (five patients) and the non-CE group (four patients), the mRNA levels of PRL and IGFBP-1 tended to be decreased in the CE group ( $P=0.06$ in both) (Fig. 3c and d).

\section{Immunohistochemistry of ERa, ER $\beta, P R A$, and PRB}

The tissues for immunohistochemistry assay were obtained from 17 patients, including nine non-CE patients and $8 \mathrm{CE}$ patients. Age, parity, gravidity, BMI, the levels of $\mathrm{E}_{2}$ and $\mathrm{P}_{4}$ and endometrial thickness were not different between the CE and non-CE groups (Table 2). ER $\alpha, E R \beta$, PRA, and PRB immunoreactivities were examined on paraffin sections in the non-CE group (Fig. 4a, c, e, and g) and the CE group (Fig. 4b, d, f, and h). The H-Scores of these receptors in stromal cells and glandular cells in the non-CE group and the CE group are shown in Fig. $3 \mathrm{i}, \mathrm{j}, \mathrm{k}$, and l. Higher expressions of ER $\alpha$ and ER $\beta$ were present in stromal cells in the CE group $(P<0.005$ and $P<0.05)$ and

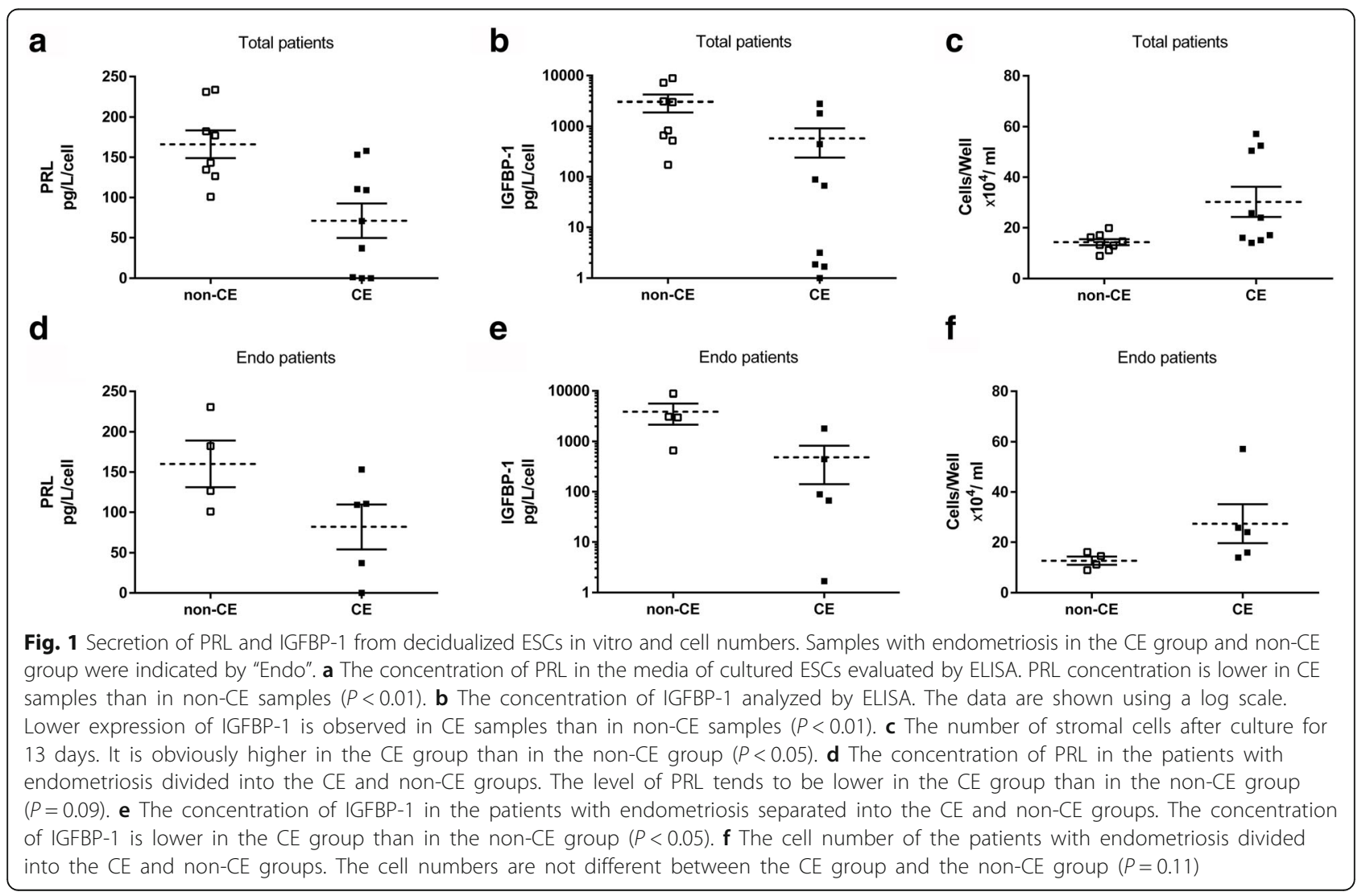



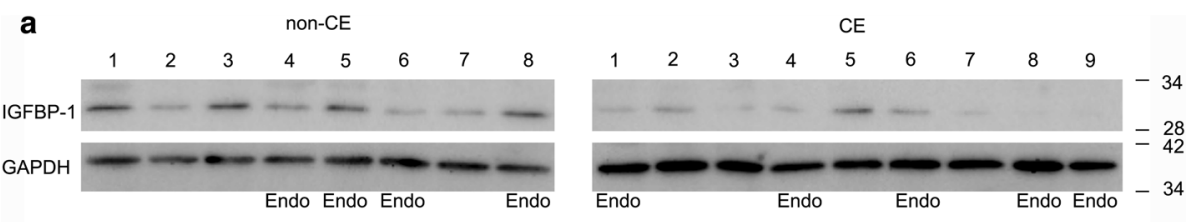

b

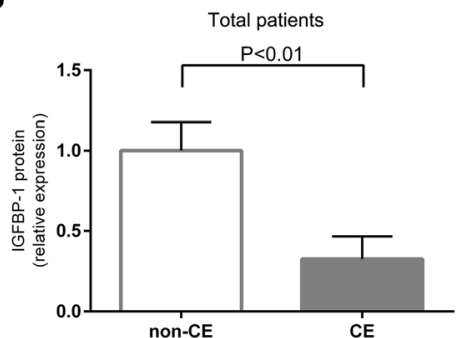

c

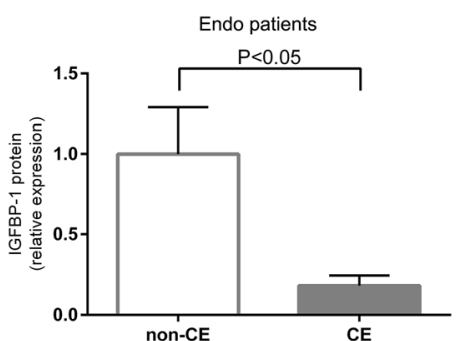

Fig. 2 Western blotting of IGFBP-1 in ESCS. Samples with endometriosis in the CE group and non-CE group were indicated by "Endo". a Western blotting of IGFBP-1 and GAPDH. Endo under the blots indicates endometriosis patient. $\mathbf{b}$ The ratio of production of IGFBP-1 per GAPDH in all patients. The production of IGFBP-1 is significantly reduced in the CE group compared to the non-CE group $(P<0.01)$. $\mathbf{c}$ The ratio of production of IGFBP-1 per GAPDH in endometriosis patients. The production of IGFBP-1 in patients with both CE and endometriosis is also decreased compared with endometriosis patients without $C E(P<0.05)$

there was a significant difference in both stromal cells and glandular cells $(P<0.05$ and $P<0.01)$, although the difference of absolute value of ER $\alpha$ and ER $\beta$ expressions in glandular cells were inconspicuous in the $\mathrm{CE}$ group in comparison with the non-CE group (Fig. 4a, b, c, d, i, and j). Higher expressions of PRA and PRB in stromal cells were seen in the CE group $(P<0.001$ and $P<0.0001)$, whereas PRA and PRB expressions were similar in the epithelia between the $\mathrm{CE}$ group and the non-CE group (Fig. 4e, f, g, h, k, and l).

\section{Discussion}

Although previous studies suggested that CE affected the uterine receptivity of the endometrium to embryo, little information is available about the mechanism. This is the first study to assess the effect of CE on decidualization of ESCs. Decidualization plays crucial roles in trophoblast invasion, the endometrial immune response of the feto-maternal interface [20, 21, 32], and the establishment of the placenta. These may suggest that disturbance of the decidualization process emerges the correlation with infertility and miscarriage [33, 34].

In the present study, the ESCs of CE had significantly lower expressions and secretion of PRL and IGFBP-1 in vitro after the induction of decidualization compared with the ESCs of non-CE. Moreover, the number of ESCs after culture for 13 days with $\mathrm{E}_{2}$ and $\mathrm{P}_{4}$ treatment to induce decidualization was significantly higher in the CE group than in the non-CE group. The modification of differentiation was connected with the promotion of proliferation. CE modifies decidualization in vitro and weakens the action of $\mathrm{P}_{4}$ on ESCs, resulting in less potential to differentiate and greater potential to proliferate. In $3 \mathrm{CE}$ patients with no or extremely low levels of PRL and IGFBP-1 secretion, the number of ESCs was extremely high, approximately 3-fold higher than that in non-CE patients (Fig. 1), and the ESCs proliferated and differentiated like as exposed to only $\mathrm{E}_{2}$.

In the culture experiment, $\mathrm{CE}$ was diagnosed in nine of 17 patients, endometriosis was diagnosed in nine of 17 patients, and five of 17 patients was suffered from CE and endometriosis. The main reason why the samples we obtained included higher percentage of $\mathrm{CE}$ and endometriosis patients is thought to be that we chose patients of endometriosis and refractory infertility when we enrolled as these were the risk of CE.

Previous studies reported that the capacity of eutopic endometrial stromal cells for decidualization was reduced, whereas the proliferation potential was increased in endometriosis patients [25]. Since the present result might be due to the effect of endometriosis, only samples with endometriosis were chosen and analyzed. Our data shown that the significantly reduced protein level and mRNA expression of PRL and IGFBP-1 and the increase of cell number were oppositely observed in the $\mathrm{CE}$ patients compared with non-CE patients, no matter whether the patients have endometriosis or not. This result suggest that $\mathrm{CE}$ affected the differentiation of cultured ESCs and modified decidualization independently of endometriosis.

Although the number of samples in this experiment was relatively low, a significant difference was apparent between $\mathrm{CE}$ and non-CE in terms of the secretion of decidual proteins and cell numbers. This may cause by the specifically developed methods for this experiment. The first thing is that the endometrial samples were 

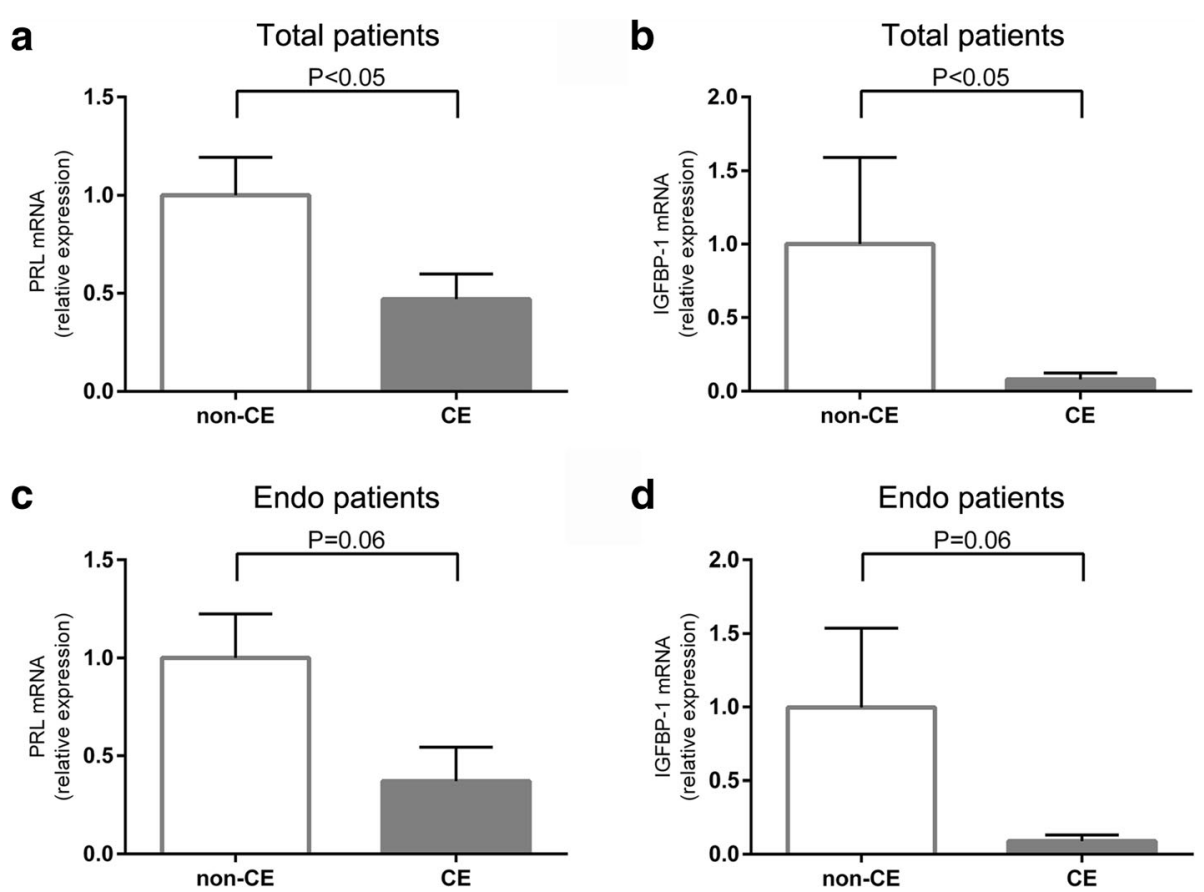

Fig. 3 The mRNA levels of PRL and IGFBP-1 in decidualized ESCs in vitro. Samples with endometriosis in the CE group and non-CE group were indicated by "Endo". a The mRNA level of PRL in the decidualized ESCs. The level is lower in the CE group. $\mathbf{b}$ The mRNA level of IGFBP-1 in the decidualized ESCs. The level is lower in the CE group. Patients with endometriosis are divided into the CE and non-CE groups. $\mathbf{c}$ and $\mathbf{d}$ the $\mathrm{mRNA}$ level of PRL and IGFBP-1tends to be lower in the CE group than in the non-CE group ( $P=0.06$ in both)

obtained in the mid-secretory phase. CE is thought to be caused by the continuous and subtle infection of some agent inside the uterus. When the ESCs obtained in the proliferative phase are used in primary culture, the induction of decidualization starts with the regulation of inflammation by antibiotics in the culture media. The removal of endometrial cells from the uterus with $\mathrm{CE}$ leads to the cessation of exposure to inflammation and immune cells in the uterus and the beginning of treatment for the infection with antibiotics in vitro. However, using the sample obtained in the secretory phase, the ESCs are already exposed to inflammation and immune cells during the initial process of decidualization in vivo.

Table 2 Clinical characteristics of the patients participating in the study for $\mathrm{IHC}$ for sex steroid hormone receptors

\begin{tabular}{lccc}
\hline & non-CE $(N=9)$ & $C E(N=8)$ & $P$ value \\
\hline Age $(\mathrm{y})$ & $37.0 \pm 1.19$ & $37.3 \pm 2.61$ & 0.24 \\
Parity & $0.44 \pm 0.24$ & $0.75 \pm 0.25$ & 0.34 \\
Gravidity & $0.11 \pm 0.11$ & $0.38 \pm 0.18$ & 0.24 \\
BMl $\left(\mathrm{kg} / \mathrm{m}^{2}\right)$ & $21.2 \pm 0.86$ & $20.7 \pm 0.86$ & 0.73 \\
E2 $(\mathrm{pg} / \mathrm{mL})$ & $109 \pm 16.9$ & $151 \pm 28.1$ & 0.093 \\
P4 $(\mathrm{ng} / \mathrm{mL})$ & $14.6 \pm 1.66$ & $18.1 \pm 3.21$ & 0.32 \\
Endometrial thickness $(\mathrm{mm})$ & $9.40 \pm 1.14$ & $8.67 \pm 1.54$ & 0.70 \\
\hline Age, parity, gravity, body $\mathrm{mass}$
\end{tabular}

Age, parity, gravidity, body mass index (BMI), the levels of E2 and P4 and endometrial thickness were not different between the $\mathrm{CE}$ and non-CE groups
As reported in the present study, the expression of sex steroid receptors is already modified at the midsecretory phase in in vivo endometrium of CE patients even with the collection of the endometrial date for the phase.

The second point is that lower concentrations of $E_{2}$ and $\mathrm{P}_{4}$ were used in the present study compared with previous studies, whereas the concentrations are identical to in vivo conditions. In many previous reports higher levels of $\mathrm{E}_{2}$ and $\mathrm{P}_{4}$ than in the in vivo condition, cyclic adenosine monophosphate (cAMP) or medroxyprogesterone acetate (MPA) have often been used to in vitro experiments to make the experiments stable [3537]. We previously reported that the difference in the response to secrete decidual proteins becomes larger among samples with a decreased $\mathrm{P}_{4}$ concentration in the medium [30]. These suggested that milder impairment of the endometrium by $\mathrm{CE}$ may be masked with exposure to higher levels of $E_{2}, P_{4}$, cAMP, or MPA.

Mishra et al. have already shown the higher expressions of ER and PR in ESCs in the secretory phase of CE patients and the result is identical to our result although the expression of hormone receptor subtypes was not investigated. The effects of estrogen develop in the endometrium through two main classical estrogen receptor (ER) isoforms, ER $\alpha$ and $E R \beta$, whereas progesterone acts by binding its two predominantly progesterone receptor 


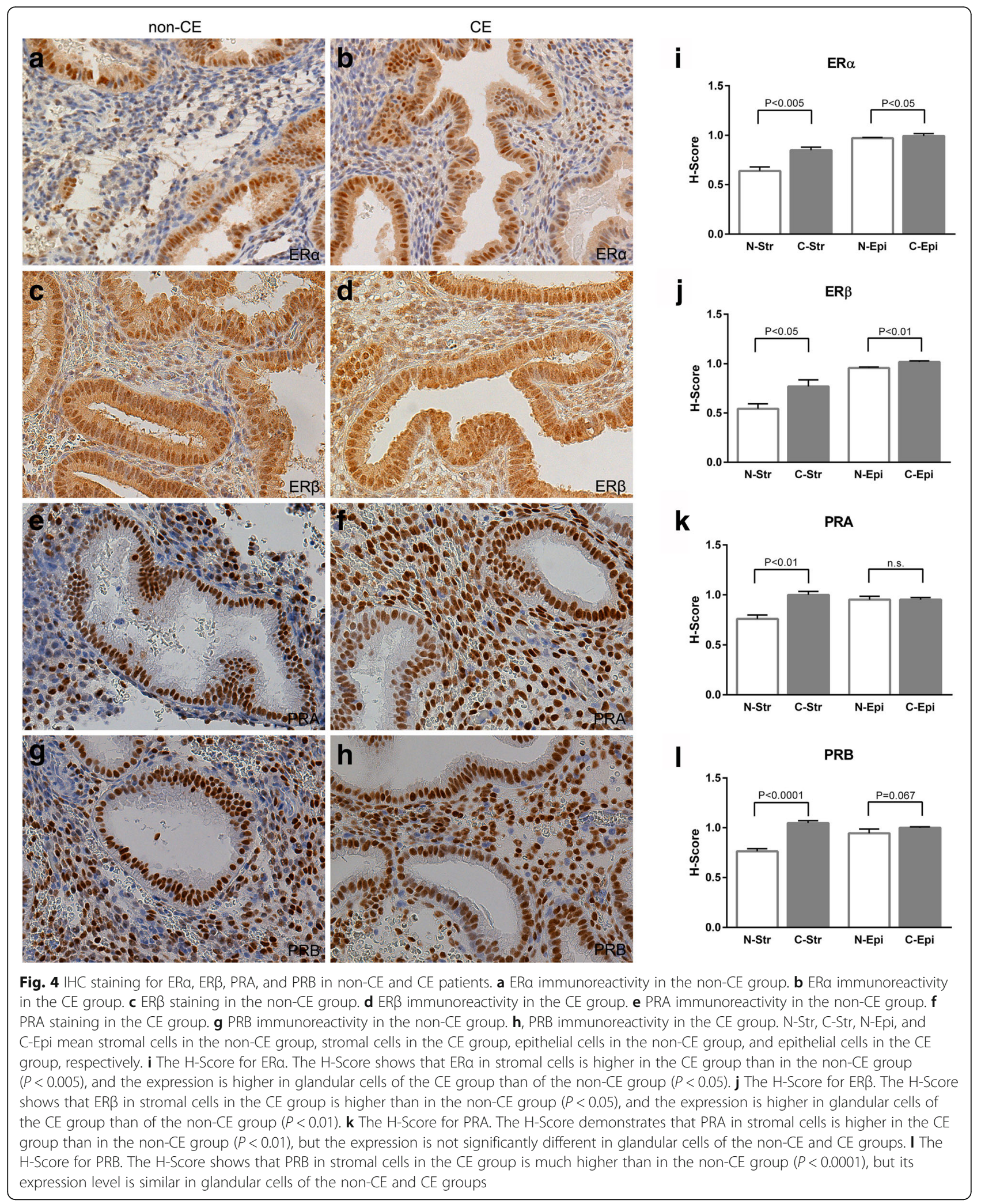


(PR) isoforms, PRA and PRB [38, 39]. ER $\alpha$ and PRA are the predominant isoforms that mediate the critical functions of the uterus for the implantation process and maintenance of pregnancy $[40,41]$. PRA is the primary mediator during the secretory phase of decidualization in humans [42]. The expressions of ER $\alpha$, PRA, and PRB decline gradually, both in glandular cells and stromal cells, during the mid-secretory phase. ER $\beta$ appears to show no change throughout the secretory phase of the menstrual cycle [42, 43]. Since there are subtypes of ER and PR and the expressions of sex steroid hormone receptors change with the menstrual cycle, the expressions of subtypes of ER and PR were examined only in endometrial samples of the mid-secretory phase with endometrial dating between day 7 and 9 after ovulation in the present study. The results showed that the immunoreactivities of $E R \alpha, E R \beta$, PRA, and PRB in stromal cells were higher in the CE group, and the expressions of ER $\alpha$ and ER $\beta$ were significantly higher in the glandular cells of the CE group. These results suggest that the expressions of ERs and PRs in stroma and ERs in epithelia are already different in the mid-secretory phase in $\mathrm{CE}$ patients, even though the endometria differentiate similarly in morphology. Furthermore, we could not detect protein expression for PRL and IGFBP-1 in the same mid secretary samples by IHC and Western blotting (data not shown). By using RT-PCR only very low or almost null levels of PRL and IGFBP-1 mRNAs were detected (Additional file 1: Figure S1). Thus, at the mid secretary phase, decidualization is still in its early phase and the secretion of decidualization markers cannot be detected. Taken together, the abnormal expression of sex hormone receptors results in difficulty for endometrium to initiate the decidualization process and modifies the development of the endometrium for decidualization.

Since CE has been reported to cause recurrent implantation failure after IVF and spontaneous abortion [9, 44], many researchers have attempted to determine why $\mathrm{CE}$ resulted in poor outcomes of the implantation process. A recent report showed that altered uterine contractility in $\mathrm{CE}$ patients leads to uterine dysperistalsis, which may be a significant cause of infertility [45]. In women with CE, an abnormal pattern of lymphocyte subsets and, consequently, an aberrant endometrial microenvironment have been demonstrated [46]. This may be another possibility explaining how $\mathrm{CE}$ affects the success of pregnancy. However, decidualization is a key process to achieve implantation and pregnancy. This is the first report showing that CE modifies the process of decidualization. Our results may provide fundamental evidences for understanding how $\mathrm{CE}$ modifies the decidualization process, consequently, influence the implantation success of IVF and spontaneous abortion.

\section{Conclusions}

In summary, the present study showed that in vitro decidualization was modified in CE patients. Furthermore, $\mathrm{CE}$ had an effect on the process of decidualization in dependently of the effect of endometriosis. The sex steroid receptors are aberrantly expressed in the endometrium of $\mathrm{CE}$ patients. These findings suggest that $\mathrm{CE}$ affects uterine receptivity for the embryo and maintenance of the pregnancy by the modification of decidualization through aberrant tuning of sex steroid hormones and their receptors.

\section{Additional file}

Additional file 1: Figure S1. The mRNA levels of PRL (a) and IGFBP-1 (b) in endometrial samples detected by RT-PCR. Total RNA was extracted from six endometrial samples (three non-CE and three CE) obtained at mid secretary phase. The expression levels of PRL and IGFBP-1 mRNAs were very low or almost null and there was no significant difference between CE group and non-CE group. (TIF $88 \mathrm{~kb}$ )

\section{Abbreviations}

BMI: Body mass index; CAMP: Cyclic adenosine monophosphate; CE: Chronic endometritis; $E_{2}$ : Estradiol; ER: Estrogen receptor; ERa: Estrogen receptor a; ERß: Estrogen receptor $\beta$; ESC: Endometrium stromal cell; IGFBP-1: Insulin-like growth factor binding protein-1; IVF: In vitro fertilization; MPA: Medroxy progesterone acetate; $P_{4}$ : Progesterone; PR: Progesterone receptor; PRA: Progesterone receptor A; PRB: Progesterone receptor B; PRL: Prolactin; RT-PCR: Reverse transcription polymerase chain reaction

\section{Acknowledgments}

The authors would like to thank the Pathology Department of Shiga University of Medical Science for making paraffin blocks and CD138 staining of paraffin sections.

\section{Funding}

This study was supported by Grant- in-Aid for Scientific Research (C) (Grant number16716425) (to F.K.). Dr. Di Wu was supported by Japan student services organization.

\section{Availability of data and materials}

The datasets supporting the conclusions of this article are available from the corresponding author on reasonable request.

\section{Authors' contributions}

Conceived: FK; designed the experiments: FK, GZ, DW; performed the experiment: DW, LZ, YN; analyzed the data: DW, FK, MI; contributed reagents/ materials/analysis tools: MI, KH, AT, AT, KT, RK; wrote the manuscript: DW, FK, GZ, TM. All authors read and approved the final manuscript.

\section{Competing interests}

The authors declare that they have no competing interests.

\section{Consent for publication}

Not applicable.

Ethics approval and consent to participate

This study was performed in accordance with the Clinical Research Guidelines of Shiga University of Medical Science, and it was approved by the research ethics committee. Infertile patients visiting our hospital were candidates, and informed, written consent was obtained when the patients participated in this study.

\section{Author details}

${ }^{1}$ Department of Obstetrics and Gynecology, Shiga University of Medical Science, Seta Tsukinowa-cho, Otsu 520-2192, Japan. ²Department of 
Obstetrics and Gynecology, 1st Affiliated Hospital, Harbin Medical University, Harbin, Heilongjiang Province 150001, China. ${ }^{3}$ Department of Clinical Sciences and Laboratory Medicine, Kansai Medical University, 2-5-1 Shin-machi, Hirakata City, Osaka 573-1010, Japan. ${ }^{4}$ Department of Clinical Laboratory Medicine, Shiga University of Medical Science, Seta Tsukinowa-cho, Otsu 520-2192, Japan.

\section{Received: 20 December 2016 Accepted: 21 February 2017} Published online: 04 March 2017

\section{References}

1. Greenwood SM, Moran JJ. Chronic endometritis morphologic and clinical observations. Obstet Gynecol. 1981;58:176-84.

2. Czernobilsky B. Endometritis and infertility. Fertil Steril. 1978;30:119-30.

3. Crum CP, Egawa K, Fenoglio CM, Richart RM. Chronic endometritis: the role of immunohistochemistry in the detection of plasma cells. Am J Obstet Gynecol. 1983;147:812-5.

4. Polisseni F, Bambirra EA, Camargos AF. Detection of chronic endometritis by diagnostic hysteroscopyin asymptomatic infertile patients. Gynecol Obstet Invest. 2003:55:205-10

5. Wild RA, Sanfilippo JS, Toledo AA. Endometrial biopsy in the infertility investigation. The experience at two institutions. J Reprod Med. 1986:31:954-7.

6. Kasius JC, Fatemi HM, Bourgain C, Sie-Go DM, Eijkemans RJ, Fauser BC, Devroey P, Broekmans FJ. The impact of chronic endometritis on reproductive outcome. Fertil Steril. 2011;96:1451-6.

7. Cicinelli E, Resta L, Nicoletti R, Tartagni M, Marinaccio M, Bulletti C, Colafiglio G. Detection of chronic endometritis at fluid hysteroscopy. J Minim Invasive Gynecol. 2005;12:514-8.

8. Johnston-Macananny EB, Hartnett J, Engmann LL, Nulsen JC, Sanders MM, Benadiva CA. Chronic endometritisis a frequent finding in women with recurrent implantation failure after in vitro fertilization. Fertil Steril. 2010;93:437-41.

9. Féghali J, Bakar J, Mayenga JM, Ségard L, Hamou J, Driguez P, Belaisch-Allart J. Systematic hysteroscopy prior to in vitro fertilization. Gynecol Obstet Fertil. 2003;31:127-31.

10. Kitaya K. Prevalence of chronic endometritis in recurrent miscarriages. Fertil Steril. 2011;95:1156-8.

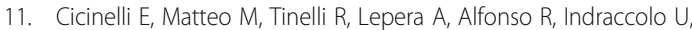
Marrocchella S, Greco P, Resta L. Prevalence of chronic endometritisin repeated unexplained implantation failure and the IVF success rate after antibiotic therapy. Hum Reprod. 2015;30:323-30.

12. Telgmann R, Gellersen B. Marker genes of decidualization: activation of the decidual prolactin gene. Hum Reprod Update. 1998;4:472-9.

13. Irwin JC, Kirk D, King RJ, Quigley MM, Gwatkin RB. Hormonal regulation of human endometrial stromal cells in culture: an in vitro model for decidualization. Fertil Steril. 1989;52:761-8.

14. Makrigiannakis A, Margioris AN, Chatzaki E, Zoumakis E, Chrousos GP, Gravanis A. The decidualizing effect of progesterone may involve direct transcriptional activation of corticotrophin-releasing hormone from human endometrial stromal cells. Mol Hum Reprod. 1999;5:789-96.

15. Petraglia F, Tabanelli S, Galassi MC, Garuti GC, Mancini AC, Genazzani AR, Gurpide E. Human decidua and in vitro decidualized endometrial stromal cells at term contain immunoreactive corticotropin-releasing factor (CRF) and CRF messenger ribonucleic acid. J Clin Endocrinol Metab. 1992;74:1427-31.

16. Florio P, Rossi M, Sigurdardottir M, Ciarmela P, Luisi S, Viganò $P$, Grasso D, Fiore G, Cobellis L, Di Blasio AM, Petraglia F. Paracrine regulation of endometrial function: interaction between progesterone and corticotropinreleasing factor (CRF) and activin A. Steroids. 2003;68:801-7.

17. Kim JJ, Jaffe RC, Fazleabas AT. Comparative studies on the in vitro decidualization process in the baboon (Papioanubis) and human. Biol Reprod. 1998:59:160-8.

18. Okada S, Okada H, Sanezumi M, Nakajima T, Yasuda K, Kanzaki H. Expression of interleukin-15 in human endometrium and decidua. Mol Hum Reprod. 2000:6:75-80.

19. Okada H, Nakajima T, Yasuda K, Kanzaki H. Interleukin-1 inhibits interleukin-15 production by progesterone during in vitro decidualization in human. $J$ Reprod Immunol. 2004;61:3-12.

20. Sharma S, Godbole G, Modi D. Decidual Control of Trophoblast Invasion. Am J Reprod Immunol. 2016;75:341-50.

21. Vinketova K, Mourdjeva M, Oreshkova T. Human Decidual Stromal Cells as a Component of the Implantation Niche and a Modulator of Materna Immunity. J Pregnancy. 2016;2016:8689436.
22. D'Hooghe TM, Debrock S, Hill JA, Meuleman C. Endometriosis and subfertility: Is the relationship resolved? Semin Reprod Med. 2003;21:243-54

23. Eskenazi B, Warner ML. Epidemiology of endometriosis. Obstet Gynecol Clin North Am. 1997:24:235-58.

24. Braundmeier AG, Fazleabas AT. The non-human primate model of endometriosis: Research and implications for fecundity. Mol Hum Reprod. 2009;15:577-86.

25. Klemmt PA, Carver JG, Kennedy SH, Koninckx PR, Mardon HJ. Stromal cells from endometriotic lesions and endometrium from women with endometriosis have reduced decidualization capacity. Fertil Steril. 2006;85:564-72.

26. Minici F, Tiberi F, Tropea A, Orlando M, Gangale MF, Romani F, Campo S, Bompiani A, Lanzone A, Apa R. Endometriosis and human infertility: A new investigation into the role of eutopic endometrium. Hum Reprod. 2008;23:530-7.

27. Takebayashi A, Kimura F, Kishi Y, Ishida M, Takahashi A, Yamanaka A, Takahashi K, Suginami H, Murakami T. The association between endometriosis and chronic endometritis. PLoS One. 2014:9:e88354.

28. Noyes RW, Hertig AT, Rock J. Dating the endometrial biopsy. Am J Obstet Gynecol. 1975;122:262-3.

29. Kasius JC, Broekmans FJ, Sie-Go DM, Bourgain C, Eijkemans MJ, Fauser BC, Devroey $\mathrm{P}$, Fatemi HM. The reliability of the histological diagnosis of endometritis in asymptomatic IVF cases: a multicenter observer study. Hum Reprod. 2012;27:153-8.

30. Kasahara K, Takakura K, Takebayashi K, Kimura F, Nakanishi K, Noda Y. The role of human chorionic gonadotropin on decidualization of endometrial stromal cells in vitro. J Clin Endocrinol Metab. 2001:86:1281-6.

31. Goulding H, Pinder S, Cannon P, Pearson D, Nicholson R, Snead D, Bell J, Elston CW, Robertson JF, Blamey RW, Ellis IO. A new immunohistochemical antibody for the assessment of estrogen receptor status on routine formalin fixed tissue samples. Hum Pathol. 1995;26:291-4.

32. Godbole G, Suman P, Gupta SK, Modi D. Decidualized endometrial stromal cell derived factors promote trophoblast invasion. Fertil Steril. 2011;95:1278-83.

33. Lee KY, DeMayo FJ. Animal models of implantation. Reproduction. 2004:128:679-95.

34. Franco HL, Jeong JW, Tsai SY, Lydon JP, DeMayo FJ. In vivo analysis of progesterone receptor action in the uterus during embryo implantation. Semin Cell Dev Biol. 2008;19:178-86.

35. Mizuno K, Tanaka T, Umesaki N, Ogita S. Establishment and characterization of in vitro decidualization in normal human endometrial stromal cells. Osaka City Med J. 1998:44:105-15.

36. Shindoh H, Okada H, Tsuzuki T, Nishigaki A, Kanzaki H. Requirement of heart and neural crest derivatives-expressed transcript 2 during decidualization of human endometrial stromal cells in vitro. Fertil Steril. 2014;101:1781-90.

37. Cho H, Okada H, Tsuzuki T, Nishigaki A, Yasuda K, Kanzaki H. Progestininduced heart and neural crest derivatives expressed transcript 2 is associated with fibulin-1 expression in human endometrial stromal cells. Fertil Steril. 2013;99:248-55.

38. Critchley HOD, Saunders PTK. Hormone receptor dynamics in a receptive human endometrium. Reprod Sci. 2009:16:191-9.

39. Li X, O'Malley BW. Unfolding the action of progesterone receptors. J Biol Chem. 2003:278:39261-4.

40. Hewitt SC, Korach KS. Oestrogen receptor knockout mice: roles for estrogen receptors alpha and beta in reproductive tissues. Reproduction. 2003;125:143-9.

41. Conneely OM, Lydon JP. Progesterone receptors in reproduction: functional impact of the A and B isoforms. Steroids. 2000;65:571-7.

42. Wang $\mathrm{H}$, Critchley HO, Kelly RW, Shen D, Baird DT. Progesterone receptor subtype $B$ is differentially regulated in human endometrial stroma. Mol Hum Reprod. 1998:4:407-12.

43. Critchley HO, Brenner RM, Henderson TA, Williams K, Nayak NR, Slayden OD, Millar MR, Saunders PT. Estrogen receptor beta, but not estrogen receptor alpha, is present in the vascular endothelium of the human and nonhuman primate endometrium. J Clin Endocrinol Metab. 2001;86:1370-8.

44. Romero R, Espinoza J, Mazor M. Can endometrial infection/inflammation explain implantation failure, spontaneous abortion and preterm birth after in vitro fertilization? Fertil Steril. 2004;82:799-804.

45. Pinto V, Matteo M, Tinelli R, Mitola PC, De Ziegler D, Cicinelli E. Altered uterine contractility in women with chronic endometritis. Fertil Steril. 2015;10:1049-52.

46. Matteo M, Cicinelli E, Greco P, Massenzio F, Baldini D, Falagario T, Rosenberg P, Castellana L, Specchia G, Liso A. Abnormal pattern of lymphocyte subpopulations in the endometrium of infertile women with chronic endometritis. Am J Reprod Immunol. 2009;61:322-9. 